account for the motions of the planets. In fact he did not, and the historical reasons for the acceptance of the heliocentric cosmology are far more complex. Osiander's notorious preface to De revolutionibus, which was almost certainly included without Copernicus's knowledge or approval, is quoted as representing Copernicus's own beliefs. (Osiander argued that the success of a theory in accounting for a series of observations in no way implies the truth of that theory. The argument is quoted by Stenger with approval, who claims that it represents the position of all modern scientists with respect to their work - a claim that many of them would dispute.) The Big Bang is repeatedly referred to as an explosion in which the material of the cosmos, initially concentrated at a central point, expands into empty space; the non-euclidian elements of relativistic cosmology are entirely ignored. And the gravitational deflection of light is presented as being purely special-relativistic in nature, no mention being made of the well-known factor-of-two error by which this attempt at an explanation fails.

Not by Design is a splendid title. It is a pity that Stenger has failed to write a book that lives up to it.

George Greenstein is a Professor in the Department of Astronomy, Amherst College, Amherst, Massachusetts 01002, USA.

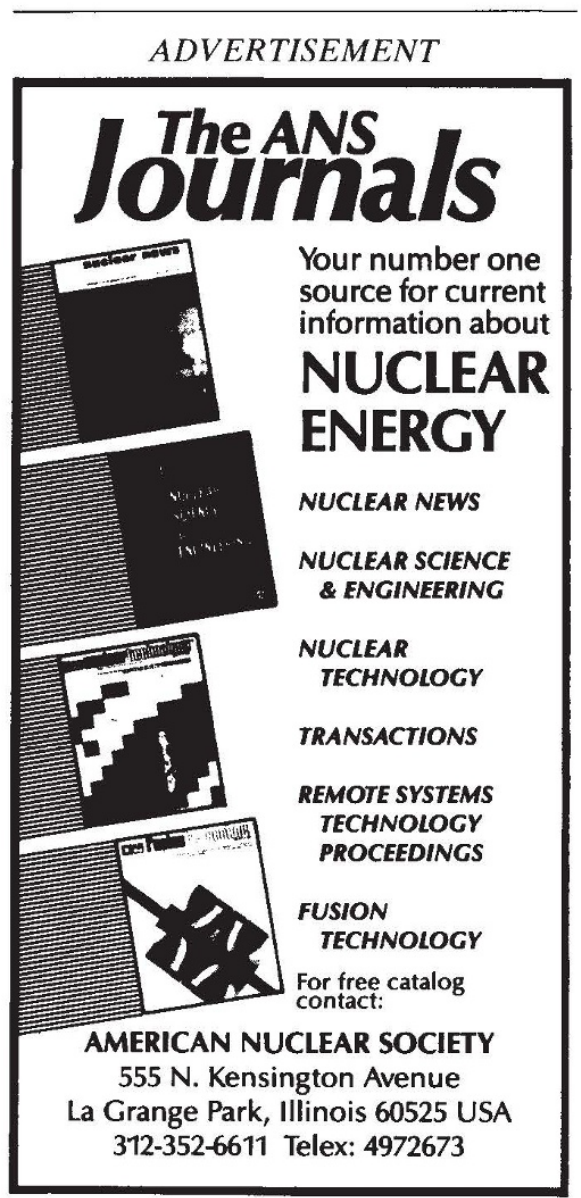

Reader Service No.22

\title{
Green genes
}

\section{Ian D. Small \& C. J. Leaver}

Plant Genetic Transformation and Gene Expression: A Laboratory Manual. Edited by John Draper, Roderick Scott, Philip Armitage and Richard Walden. Blackwell Scientific: 1988. Spiral bound pp. 355. $£ 29.50, \$ 66.50$.

Plant Molecular Biology Manual. Edited by Stanton B. Gelvin and Robert A. Schilperoort. Kluwer: 1988. Loose-leaf core manual pp.400. Dfl. 110, £31.50, $\$ 52.50$.

EVERY laboratory has a set of protocols which evolve on scraps of paper, annotated with the latest modifications, ready for production as THE LAB MANUAL. Few such manuals make it to the presses, and fewer still become classics. But in an expanding field like plant molecular biology the opportunity is there for a beginner's practical manual to make a big impact, and the candidates are appearing thick and fast.

Although there is no substitute for hands-on experience, Plant Genetic Transformation and Gene Expression is the next best thing. Based on a course run at Leicester University, it is clearly written, well laid out, helpfully illustrated and covers the basics of the field comprehensively. Its six chapters deal with vectors for gene transfer, plant transformation using Agrobacterium (the largest chapter), direct DNA uptake into protoplasts (with or without electroporation), isolation of plant nucleic acids, Southern blot analysis of plant nuclear DNA and the analysis of gene expression in transgenic plants. A welcome extra is a list of addresses of companies cited in the text as suppliers of equipment and materials, although it will be of more use to readers in Europe than those elsewhere. All in all, the book has been thoroughly designed to enable a laboratory with little previous experience of molecular biology or plant tissue culture to start work with these techniques.

Plant Molecular Biology Manual comes in a loose-leaf binder, and providing you have the funds to buy them, and the editors keep their promise, updates will become available as the techniques change and new technologies are devised. The manual is divided into three sections: introduction of DNA into plant cells (nine chapters), expression of genes in plants (seven chapters) and the fate of introduced genes (two chapters). Each of the chapters is self-contained and is written by specialists, who, in most cases, have considerable expertise on the particular facet of plant molecular biology involved.

This type of book has its disadvantages, and in comparison with Plant Genetic Transformation it suffers from a lack of continuity and cohesion; for example, different protocols for the same technique appear in different chapters (with no cross-referencing). Unlike the other book, there is no index, so hunting for a particular technique (with no way of knowing whether it is included) can be frustrating. The compensating advantage is the wider scope achieved by having so many contributors, which allows the inclusion of several additional subjects, among them the construction of cDNA and genomic clone banks, chromatin structure, DNA methylation, translation of in vitro generated mRNA in Xenopus oocytes and RFLP mapping.

Where there is duplication between the two manuals, Plant Genetic Transformation is more comprehensive, and offers more practical advice to beginners. Protocols often differ slightly between the two books due to the use of different plant material. Plant cells and tissue taken from different species, or from the same species grown under different conditions, or even from different parts of the same plant, often require modifications of the same technique. Draper and his colleagues attempt to get round this problem by describing experiments to optimize new systems in addition to giving protocols for the systems they use. Gelvin and Schilperoort confine themselves to providing references for protocols with other known systems. Both books appear reasonably up to date, although the omission of a description of the promising new reporter gene $\beta$-glucuronidase (GUS) in either of Plant Molecular Biology Manual's two chapters on reporter genes is unfortunate.

For the worker new to the field, Plant Genetic Transformation is ideal. Groups with a specific idea of the plant system and techniques they wish to use should check which book has better coverage for their purposes, while researchers who already have a working transformation system may prefer the greater variety of techniques in Plant Molecular Biology Manual. Preferably, of course, one should have both!

Ian D. Small and C.J. Leaver are in the Department of Botany, University of Edinburgh, The King's Buildings, Mayfield Road, Edinburgh EH9 $3 J H, U K$

- With two new spiral-bound ('bench-top format') books on its list, Academic Press is also a player in the growth business of publishing practical manuals in plant molecular biology.

Methods for Plant Molecular Biology, edited by Arthur Weissbach and Herbert Weissbach, is aimed at graduate students and more experienced researchers, and consists of articles chosen from Vol. 118 of the series Methods in Enzymology. Price is $\$ 45, £ 31.50$. Mary A. Schuler and Raymond E. Zielinski's Methods in Plant Molecular Biology is due to appear later this year, and is an introduction to various techniques primarily intended for students. Price is $\$ 29.95, £ 19$. 